\title{
What Are the Consequences When the New Year Eve in Iran Coincides With COVID-19?
}

\author{
Gholamreza Farnoosh $^{1}$ Q , Kazem Hassanpour ${ }^{2}$ Q Taleb Badri $^{3}$ Q , Seyed Reza Hosseini Zijoud ${ }^{*}$ \\ 1. Applied Biotechnology Research Center, Baqiyatallah University of Medical Sciences, Tehran, Iran. \\ 2. Department of Pediatrics, School of Medical, Sabzevar University of Medical Sciences, Sabzevar, Iran. \\ 3. Neuroscience Research Center, Baqiyatallah University of Medical Sciences, Tehran, Iran.
}

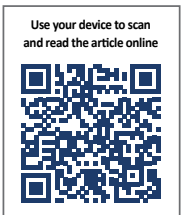

Citation Farnoosh Gh, Hassanpour K, Badri T, Hosseini Zijoud SR. What Are the Consequences When the New Year Eve in Iran Coincides With COVID-19? Research in Molecular Medicine. 2020; 8(2):49-50. https://doi.org/10.32598/rmm.8.2.1145.1

https://doi.org/10.32598/rmm.8.2.1145.1

n March 11, 2020, the World Health Organization (WHO) announced the pandemic outbreak of coronavirus disease 2019 (COVID-19), due to severe acute respiratory syndrome coronavirus 2 (SARS-CoV-2), which began in December 2019 in Wuhan, China [1].

Iran was the 25th country affected by COVID-19. According to the Iranian Ministry of Health, every 12 minutes, one person dies in Iran because of COVID-19. After a 3.5-fold and 12.9-fold increase in the number of COVID-19 affected people and deaths, respectively in the second two weeks compared with the first two weeks after the official announcement of COVID-19 on February 19, 2020, in Iran [2], the coincidence of this epidemic with the celebration of New Year Eve, may lead to a human and health catastrophe in Iran.

Nowruz (New Year Eve) is the first day of the Iranian New Year on March 20 (or the previous or following day). It marks the beginning of spring in the Northern Hemisphere and takes place with celebrations.

Before the start of the New Year in Iran on March 20, all 31 provinces were affected by COVID-19, with some provinces including Qom, Tehran, Guilan reporting the highest prevalence rates [2].
The preparations for the celebration of New Year's Eve in Iran include shopping in crowded markets and beginning of the New Year Eve holiday in Iran (6 official days for administrations and 13 days for schools and universities) is along with traveling, that accelerates human-to-human transmission, effectively spreading SARS-CoV-2 [3].

Due to the outbreak of COVID-19 during Nowruz, abroad travel had decreased, but domestic travel in Iran had not stopped. Despite the closing of museums and recreation centers, and repeated official announcements that no amenities will be offered, Nowruz trips continued. Besides domestic tourism attractions in Iran as a four-season country, many people in big cities are returned to their villages and hometowns for the New Year's holiday to visit their parents or grandparents. These visits can lead to an increased prevalence of COVID-19 in adults, which is dangerous and worrying.

This year, with the beginning of Nowruz, major highways and tourist areas were hit by heavy traffic, too. Nowruz trips of three million Iranians from the 13 affected provinces with COVID-19 (during March 17-20, 2020) demonstrated that many people refused to stay at home, while Iranian authorities and the WHO have repeatedly urged people not to travel, in order to prevent the spread of SARS-CoV-2 [2].

\section{* Corresponding Author:}

Seyed Reza Hosseini Zijoud, PhD

Address: Applied Biotechnology Research Center, Baqiyatallah University of Medical Sciences, Tehran, Iran

Phone: +98 (21) 880053609

E-mail: hosseini7sr@gmail.com 
Quarantine of cities with COVID-19 cases and controlling citizens' traffic to these cities are strategies recommended by WHO to control the outbreak of SARS$\mathrm{CoV}-2$, and China's experience as the main sources of this outbreak has confirmed the effectiveness of the measure [4]. But no quarantine in any city had been implemented in Iran. Although some traffic restrictions had been put in place, they were not fully enforced in any province. According to the Iranian Ministry of Roads and Urban Development, the number of Nowruz travelers has decreased from 18 million in 2019 to 8.5 million in 2020. However, this amount of travel is alarming [5].

The Iranian Ministry of Health had repeatedly stated that the only way to control the SARS-CoV-2 outbreak is social distasting by reducing contact levels, traffic, traveling, and canceling unnecessary trips in Nowruz, as well as staying at home under voluntary home quarantine. But the opportunity to travel on the Nowruz holiday and the "high season" in Iran, had become a serious threat to public health. Because the incubation period of COVID-19 is 2 to 14 days, and every infected or carrier can infect 2 to 20 people in Iran, traveling to different cities during Nowruz may lead to devastating outbreaks.

As such, traveling seems to be spreading SARS-CoV-2 to the farthest cities and villages after the Nowruz holidays, which certainly do not have adequate health facilities. In big cities, hospitals will not have the capacity to accommodate patients, so human and health consequences are predictable. Nowruz trips like a cluster bomb will exacerbate the wave of COVID-19 across the country, and Nowruz celebrations have made it harder to maintain control of the disease in Iran.

\section{Ethical Considerations}

\section{Compliance with ethical guidelines}

All ethical principles were considered in this article.

Funding

This research did not receive any specific grant from funding agencies in the public, commercial, or not-forprofit sectors.

\section{Authors contribution's}

Writing the manuscript: Gholamreza Farnoosh, Seyed Reza Hosseini Zijoud; Design, supervision: Kazem Hassanpour, Taleb Badri; Reading and approving the final manuscript: All authors.

\section{Conflict of interest}

The authors declared no conflict of interests.

\section{Acknowledgements}

The authors would like to thank the Clinical Research Development Unit of Baqiyatallah Hospital, Tehran, Iran. The authors dedicate special thanks to Caroline Mcgown for English editing.

\section{References}

[1] World Health Organization. WHO challenges misinformation about COVID-19 and smoking on World No Tobacco Day. [Internet]. 2019 [Updated April 4, 2020]. Availble from: https://www.who.int/emergencies/diseases/novel-coronavirus-2019/events-as-they-happen

[2] Rouhani H. Public cooperation for overcoming coronavirus biggest new-year present/ Infrastructures fully strong for fighting COVID-19/ All our grocery stores active/ I hope we won't need to fine anyone in implementing social distancing plan. President at the session of National task force for fighting Coronavirus [Internet]. 2020 [Updated $28 \mathrm{Mar}$ 2020]. Available at: http:// president.ir/en/114453

[3] Sun Q, Qiu H, Huang M, Yang Y. Lower mortality of COVID-19 by early recognition and intervention: Experience from Jiangsu Province. Annals of Intensive Care. 2020; 10(1):1-4. [DOI:10.1186/s13613-020-00650-2] [PMID] [PMCID]

[4] Pan X, Ojcius DM, Gao T, Li Z, Pan C, Pan C. Lessons learned from the 2019-nCoV epidemic on prevention of future infectious diseases. Microbes and Infection. 2020; 22(2):86-91. [DOI:10.1016/j.micinf.2020.02.004] [PMID] [PMCID]

[5] Ghorbani M. [A 70 percent drop in public passenger trave due to the outbreak of the corona virus (Persian)] [Internet] 2020 [Updated 1 Apr 2020]. Available at: https://www. mrud.ir/news-view/ArticleId/24597/ 